Check for updates

Montreal, Canada

Cite this as: BMJ 2020;371:m3985 http://dx.doi.org/10.1136/bmj.m3985 Published: 14 October 2020

\section{Covid-19: Eli Lilly pauses antibody trial for safety reasons}

\section{Owen Dyer}

The phase III trial of a leading candidate treatment for covid-19 has been put on hold for safety reasons after five days of treatment, and a week after its maker applied for a US emergency use authorisation.

A spokeswoman for the National Institutes of Health said that the Activ-3 trial of Eli Lilly's neutralising antibody LY-CoV555 (bamlanivimab) "reached a predefined boundary for safety at day five, meaning an overall difference in clinical status between the group receiving LY-CoV555 and the group receiving saline placebo."

No further details have been released. The Activ-3 trial is studying 326 subjects hospitalised with mild to moderate covid-19. It has a two stage format, with 700 more subjects being recruited if the early stages go well. But all recruitment as well as treatment is now on hold.

Another phase III trial, Activ-2, is studying the same antibody in patients with mild to moderate covid-19 who are not hospitalised. It is unaffected by the pause.

Both trials compare standard treatment plus the antibody against standard treatment plus placebo. In the case of Activ-3, standard treatment includes remdesivir.

The halt was called "out of an abundance of caution" by the trial's data and safety monitoring board (DSMB), an independent group of experts. The trial remains blinded, so neither the treating physicians nor Eli Lilly know which patients were receiving treatment and which placebo. The board will review the data at a meeting set for 26 October and make a recommendation on whether to resume.

"Lilly is supportive of the decision by the independent DSMB to cautiously ensure the safety of the patients participating in this study," the company said in a statement.

On 7 October, Eli Lilly sought a Food and Drug Administration (FDA) emergency use authorisation for bamlanivimab in higher risk patients recently diagnosed with mild to moderate covid-19. ${ }^{1}$

Activ-3 is the second major covid-19 trial to be halted this week, following Monday's pausing of Johnson and Johnson's vaccine trial over an unexplained illness in a study participant. ${ }^{2}$

The US arm of the AstraZeneca Oxford covid-19 vaccine trial was also stopped. ${ }^{3}$ After a UK patient developed transverse myelitis last month, the trial was paused around the world, then swiftly restarted, except in the US where it remains on indefinite hold as the FDA carries out a safety investigation.

Eli Lilly. Lilly provides comprehensive update on progress of SARS-CoV-2 neutralizing antibody programs. 7 October 2020. https://investor.lilly.com/news-releases/news-release-details/lilly-provides-comprehensive-update-progress-sars-cov-2

Mahase E. Covid-19: Johnson and Johnson vaccine trial is paused because of unexplained illness in participant. BMJ2020;371:m3967doi: 10.1136/bmj.m3967.

Mahase E. Covid-19: Oxford researchers halt vaccine trial while adverse reaction is investigated. BMJ2020;370:m3525doi: 10.1136/bmj.m3525. 